\title{
Parenchymal mucinous cystadenoma of the kidney: a case report and literature review
}

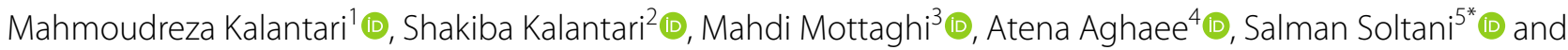 \\ Behtash Pedram $\operatorname{Rad}^{5}$ (D)
}

\begin{abstract}
Background: Mucinous cystadenoma (MC) of the kidney is exceedingly rare. We found 22 similar cases in the literature. These masses are underdiagnosed due to radiologic similarities with simple renal cysts.

Case presentation: A 66-year-old man with a previous history of hypertension and anxiety was referred to our tertiary clinic with left flank pain. Ultrasound revealed a $60 \mathrm{~mm}$-sized, complex cystic mass with irregular septa in the lower pole of the left kidney (different from last year's sonographic findings of a simple benign cyst with delicate septa). CT scan showed the same results plus calcification. Due to suspected renal cell carcinoma, a radical nephrectomy was performed. Postoperative histopathologic examination revealed a cyst lined by a single layer of columnar mucin-producing cells with small foci of pseudo-stratification, consistent with the MC's diagnosis. The first follow-up visit showed normal blood pressure without medication and no flank pain and anxiety after a month.

Conclusion: It is quite challenging to distinguish the primary MC of the kidney from a simple renal cyst based on clinical and imaging findings. The radiologic features of these entities overlap significantly. Thus, complex renal cyst and renal cysts with mural nodules should be followed closely to detect malignancy earlier.
\end{abstract}

Keywords: Mucinous cystadenoma, Mucinous cystadenocarcinoma, Renal pelvis, Pyelocaliceal system, Case report

\section{Background}

The most common renal pelvis neoplasms are transitional renal carcinomas followed by squamous cell carcinomas. Each contributes to $85-90 \%$ and $10-15 \%$ of cases, respectively [1]. Adenocarcinomas (subclassified as tubulovillous, mucinous, and papillary non-intestinal) and small-cell carcinomas of the renal pelvis account for less than $1 \%$ of renal neoplasms $[1,2]$. Mucinous cystic neoplasms of the kidney are exceedingly rare that they are not even entered into WHO's classification [3]. These tumors' preoperative diagnosis is usually tricky and confusing because they look like a simple renal cyst on imaging [3]. Knowledge about the diagnosis and treatment

\footnotetext{
*Correspondence: SoltaniS@mums.ac.i

${ }^{5}$ Kidney Transplantation Complications Research Center, Mashhad

University of Medical Sciences, Mashhad, Iran

Full list of author information is available at the end of the article
}

of these tumors is limited. Here, we described a case of mucinous cystadenoma (MC) of the kidney.

\section{Case presentation}

A 66-year-old man was referred to the urologist by the primary care physician because of left flank pain and a left cystic renal mass $(6 \mathrm{~mm})$, which was detected on ultrasound. Past medical history was remarkable of anxiety, pernicious anemia, sensory-neural hearing loss, and a five-year history of hypertension. An ultrasound performed one year earlier due to hypertension surveillance detected a $50 \mathrm{~mm}$, benign renal cyst in the lower pole of the left kidney with fine septa and no calcification. He had no palpable mass, hematuria, and flank pain then. Repeated ultrasonography showed a 58*48*61 mm-sized, complex cystic mass with irregular septa and few echogenic particles in the lower pole of the left kidney. He was taking vitamin B12 supplementation for pernicious anemia and losartan for hypertension. Family, psychological, 
Table 1 The patient's pre- and postoperative laboratory values

\begin{tabular}{lll}
\hline Parameter & $\begin{array}{l}\text { June 2018 } \\
\text { (preoperational) }\end{array}$ & $\begin{array}{l}\text { February 2019 } \\
\text { (postoperational) }\end{array}$ \\
\hline WBC count $(\times 109 / \mathrm{L})$ & 6.6 & 5.8 \\
Hemoglobin $(\mathrm{g} / \mathrm{dl})$ & 13.2 & 13.9 \\
Platelet count $(\times 109 / \mathrm{L})$ & 168 & 166 \\
Mean corpuscular volume (fL) & 84.7 & 87.4 \\
Creatinine (mg/dl) & 1.7 & 1.9 \\
Alanine aminotransferase (U/L) & 33 & 21 \\
Aspartate aminotransferase & 30 & 26 \\
$\quad$ (U/L) & & \\
Ferritin (ng/mL) & 69.3 & 41.2 \\
Folic acid $(\mathrm{ng} / \mathrm{mL})$ & 7.8 & 15 \\
Vitamin B12 (pg/mL) & 550 & 464 \\
Urine analysis & Bland & Bland \\
PSA (ng/mL) & 0.9 & - \\
\hline
\end{tabular}

and social history were unremarkable. Physical examination and laboratory studies were all within normal limits (Table 1).

Abdominopelvic computed tomography $(\mathrm{CT})$ showed a cystic lesion measuring $64 * 51 \mathrm{~mm}$-sized in the lower pole of the kidney with fine septa and two echogenic foci compatible with calcification (Fig. 1). These findings were compatible with the Bosniak IIF category. There was no evidence of extra-cystic extension or distant metastasis in the abdominopelvic cavity. We performed radical nephrectomy through the left flank approach without any complication, and he was discharged three days later.

Macroscopic examination: The kidney was $662 \mathrm{~g}$. The specimen measured $10 * 7 * 6 \mathrm{~cm}$ with surrounding perirenal fat-measuring in thickness from 0.5 to $1.0 \mathrm{~cm}$. Ureter extends from renal pelvis $(5.0 \mathrm{~cm}$ in long, $0.6 \mathrm{~cm}$ diameter), renal vein $(1.0 \mathrm{~cm}$ long, $0.8 \mathrm{~cm}$ diameter), and renal artery (1.0 cm long, $0.3 \mathrm{~cm}$ diameter). A circumscribed mass measuring $6 * 6 * 5 \mathrm{~cm}$ was detected in the middle pole. A cross section of the mass revealed a unilocular cyst in renal parenchyma. It was located at the medulla and cortex with a smooth, glistering, and yellow inner surface without papillary projections or solid nodules. The content of the cyst was thickly mucinous and gelatinous materials. The tumor pushed against the renal capsule but did not appear to penetrate the capsule or invade into the perirenal fat.

Microscopic examination: The microscopic section revealed a cyst lined by columnar mucin-producing cells of endocervical type. The lining epithelium was a single layer but small foci of pseudo-stratification and simple, delicate papillary folds. The nuclei were basally located, round, uniform, and vesicular with one small nucleolus. Cyst content was myxoid and acidophilic
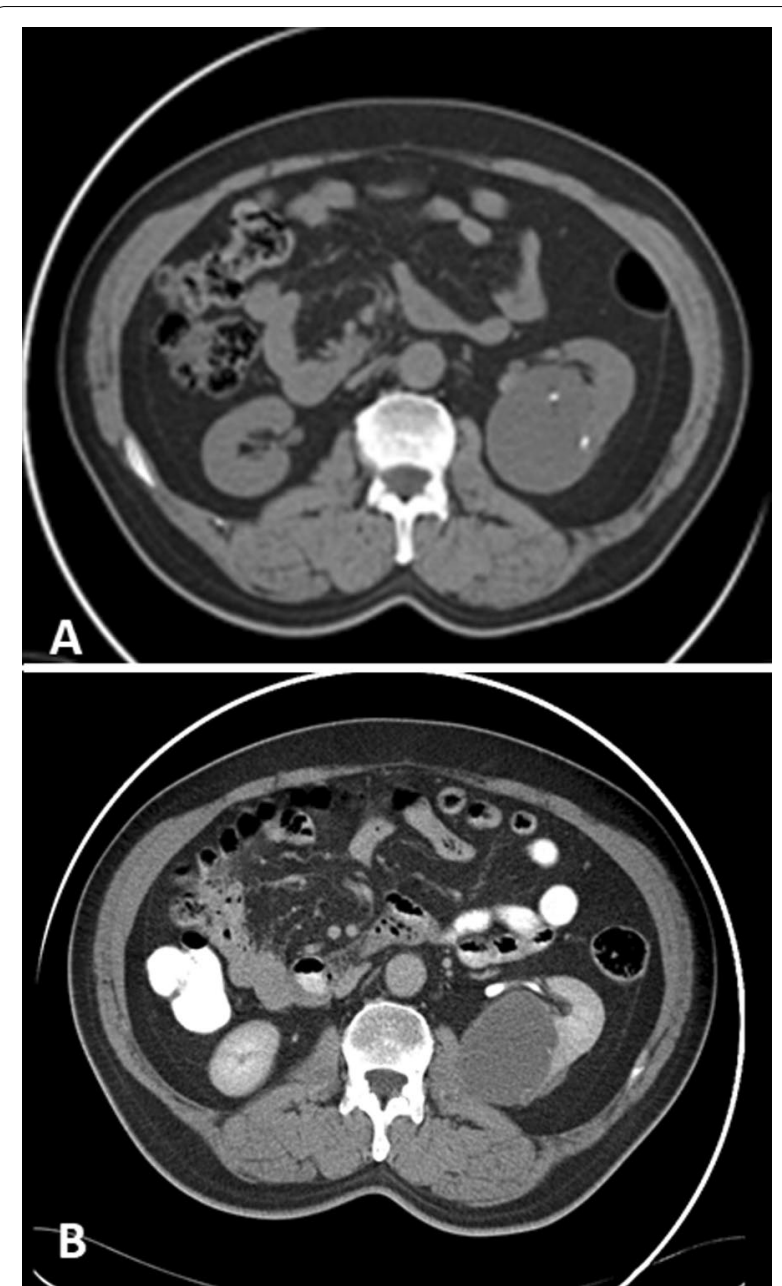

Fig. 1 An unenhanced axial CT scan shows a well-defined low-attenuated mass compatible with a cyst. Renal cyst calcification is depicted (A). Axial enhanced CT scan in the excretory phase shows no delayed internal enhancement and no association with the pyelocalyceal system. External pressure on the pyelocalyceal system without invasion is noted (B)

depositions with foamy macrophages, hemosiderinladen macrophages, and cholesterol clefts. The cyst wall was fibrotic with foci of calcification plus aggregations of hemosiderin-laden and foamy macrophages. Peri-cystic renal parenchyma showed atrophic tubules, sclerotic glomeruli, lymphocyte-predominant leukocyte infiltration, and lymphoid follicles with germinal center (Fig. 2). The final diagnosis of $\mathrm{MC}$ of renal parenchyma was made. Chest CT scan performed, which was negative for metastasis. We did not perform IHC studies due to limited resources.

Interestingly, a follow-up visit after one month revealed no flank pain, normal blood pressure without any medication, improved hearing status, and no experience of 


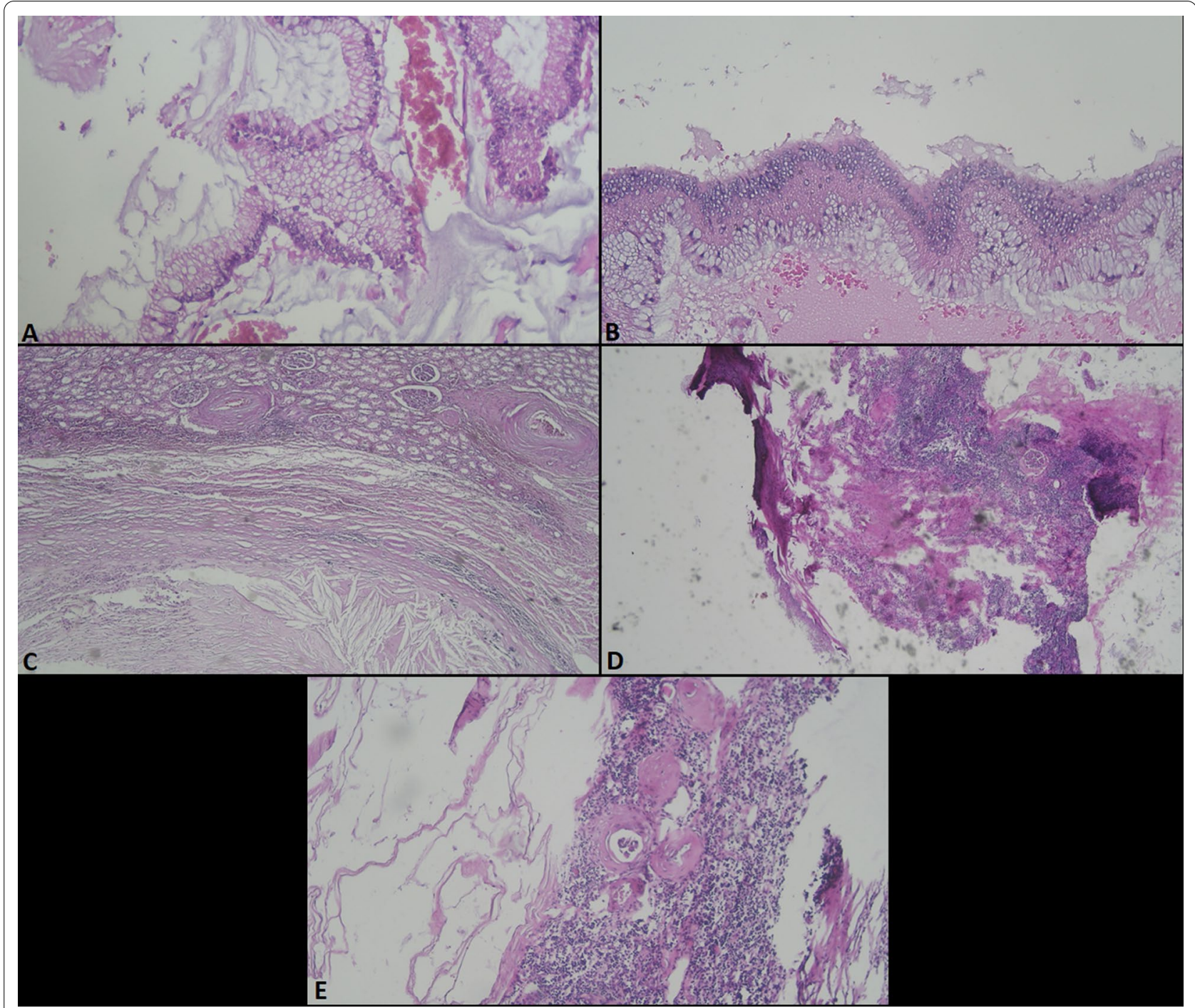

Fig. 2 Microscopic sections show renal cyst lined by a single layer of columnar mucinous epithelium (A), with focal pseudo-stratification (B). The cyst contains mucoid material and cholesterol clefts (C). Peri-cystic renal parenchyma reveals chronic leukocyte infiltration (D \& E)

anxiety attacks. He is in the same state of health during the 9-month follow-up.

\section{Discussion}

We report a rare $\mathrm{MC}$ of the kidney in a patient with progressive radiologic findings from the benign simple renal cyst to a complex cyst.

\subsection{Epidemiology}

Including our case, only 23 cases of MCs were reported in the English literature (Table 2). Thirteen patients were male, eight were female, and two are unknown $[4,5]$. The cysts' median size (excluding cases that have not mentioned cyst size) was 16.5 (range: $2.4-37 \mathrm{~cm}$ ). Similarly, the median age was 60.5 (range: 79-27 years). Its malignant counterpart, mucinous cystadenocarcinoma (MCC), is also a rare entity with only thirteen literature reports. The features defining malignancy are nuclear atypia, invasion of stroma, and multilayers of neoplastic cells $[6,7]$. Most of the reported cases of these neoplasms were from Japan, followed by India, Mexico, Iran, and Turkey (Table 1) $[8,9]$.

\subsection{Etiology}

Among the previous cases, most of them originated from the urinary collecting system (pelvic MC) and less from renal parenchyma (parenchymal $\mathrm{MC}$ ), including our case $[3,10-19]$. There are three theories about glandular 
Table 2 Previous case reports on MC and MCC

\begin{tabular}{|c|c|c|c|c|c|c|c|c|}
\hline Study & Sex & Age & Location & Size & Type & $\begin{array}{l}\text { Lithiasis/ } \\
\text { Pyelonephritis }\end{array}$ & Region & IHC \\
\hline Tamsin $^{6} 2019$ & $\mathrm{~F}$ & 65 & L & 16 & $\mathrm{MCa}$ & $-1-$ & Europe, Belgium & CEA - \\
\hline Geramizadeh $^{32} 2017$ & M & 73 & L & N/A & MuC & $-/-$ & Asia, Iran & NS \\
\hline Xiang 212017 & M & 75 & $\mathrm{R}$ & 15 & & $-1-$ & Asia, China & GATA3 + \\
\hline $\mathrm{Kim}^{20} 2016$ & M & 55 & $\mathrm{R}$ & 5.5 & $\mathrm{MCa}$ & $-1-$ & Asia, S Korea & $\begin{array}{l}\text { CK7, CD20, EMA, MUC-2, MUC-5AC+, } \\
\text { CEA + (focally) } \\
\text { Vimentin - }\end{array}$ \\
\hline Joseph $^{20} 2016$ & M & 51 & Horseshoe & 15 & $\mathrm{MCa}$ & NS/NS & Asia, India & NS \\
\hline Mitome $e^{18} 2015$ & M & 45 & Horseshoe & 16.5 & MuC & $-1-$ & Asia, India & NS \\
\hline $\operatorname{Han}^{1} 2015$ & M & 50 & $\mathrm{R}$ & 5.7 & $\mathrm{MCa}$ & \pm & Asia, S Korea & NS \\
\hline Patel $^{2} 2014$ & $\mathrm{~F}$ & 45 & $\mathrm{R}$ & 17 & $\mathrm{MCa}$ & $+/+$ & Asia, India & NS \\
\hline Yadav 242013 & M & 45 & Ectopic & 1.9 & $\mathrm{MCa}$ & $+/+$ & Asia, India & NS \\
\hline Chablé $^{3} 2013$ & $\begin{array}{l}M \\
M \\
M\end{array}$ & $\begin{array}{l}64 \\
54 \\
45\end{array}$ & $\begin{array}{l}R \\
L \\
L\end{array}$ & $\begin{array}{l}37 \\
20 \\
2.4\end{array}$ & $\begin{array}{l}\text { MuC } \\
\text { MuC } \\
\text { MuC }\end{array}$ & $\begin{array}{l}+/ N S \\
N S / N S \\
-/ N S\end{array}$ & N America, Mexico City & $\begin{array}{l}\text { MUC-2, MUC-5AC+ } \\
\text { CK7 and CEA + (focally) } \\
\text { Synaptophysin, CD56, chromogranin - }\end{array}$ \\
\hline Sonmez 2013 & M & 67 & L & 20 & $\mathrm{MCa}$ & $-/-$ & Europe, Turkey & $\mathrm{CK} 7, \mathrm{CK} 20+$ \\
\hline Tepeler ${ }^{37} 2011$ & M & 60 & L & 7 & $\mathrm{MCa}$ & $-/-$ & Europe, Turkey & $\begin{array}{l}\text { CK7, CEA, EMA+ } \\
\text { CK20- }\end{array}$ \\
\hline Raphael $^{23} 2011$ & M & 56 & $\mathrm{R}$ & 16 & $\mathrm{MCa}$ & \pm & Asia, India & NS \\
\hline Kumar $^{13} 2009$ & M & 63 & $\mathrm{R}$ & 21 & MuC & $+/+$ & Asia, Nepal & NS \\
\hline Kawahara ${ }^{34} 2009$ & M & 50 & $\mathrm{R}$ & 4.5 & MuC & $-/ N S$ & Asia, Japan & MUC-2, chromogranin A, synaptophysin + \\
\hline $\mathrm{RaO}^{22} 2009$ & M & 52 & L & 35 & MuC & \pm & S America, Brazil & $\begin{array}{l}\text { CK7, CK } 20+ \\
\text { CDX2- }\end{array}$ \\
\hline Fareghi ${ }^{33} 2009$ & M & 45 & L & 30 & $\mathrm{MCa}$ & $+/+$ & Asia, Iran & NS \\
\hline Gangane ${ }^{15} 2008$ & $\begin{array}{l}F \\
M\end{array}$ & $\begin{array}{l}35 \\
65\end{array}$ & $L$ & NS & $\begin{array}{l}\mathrm{MuC} \\
\mathrm{MuC}\end{array}$ & $\begin{array}{l}\text { NS/NS } \\
+/+\end{array}$ & Asia, India & NS \\
\hline Charfi' $^{12} 2008$ & $\mathrm{~F}$ & 31 & $\mathrm{R}$ & 13 & MuC & NS/NS & North Africa, Tunisia & CK7, EMA + \\
\hline Mardi ${ }^{19} 2006$ & $\mathrm{~F}$ & 62 & NS & NS & MuC & NS/NS & Asia, India & NS \\
\hline Akan ${ }^{10} 2005$ & $\mathrm{~F}$ & 27 & Horseshoe & 12 & MuC & $-1-$ & Europe, Turkey & NS \\
\hline Takashi ${ }^{35} 2003$ & $\mathrm{~F}$ & 53 & $\mathrm{R}$ & 27 & MuC & $+/ \mathrm{NS}$ & Asia, Japan & $\begin{array}{l}\text { CA19-9, neuron-specific enolase, chro- } \\
\text { mogranin A+ }\end{array}$ \\
\hline Park ${ }^{17} 2002$ & M & 79 & $\mathrm{R}$ & 3.5 & MuC & $+/+$ & N America, USA & NS \\
\hline Toyoda $^{31} 1997$ & M & 69 & $\mathrm{R}$ & 5 & Muc & $-/ N S$ & Asia, Japan & $\begin{array}{l}\text { CEA, CK, CA19-9, EMA, S100, chromogra- } \\
\text { nin - }\end{array}$ \\
\hline Muraoka 1997 & NS & NS & Supernumerary & NS & $\mathrm{MCa}$ & NS/ NS & Asia, Japan & NS \\
\hline Ohyabu ${ }^{16} 1990$ & $\mathrm{~F}$ & 63 & $\mathrm{R}$ & NS & MuC & \pm & Asia, Japan & NS \\
\hline Arakawa $^{14} 1989$ & $\mathrm{~F}$ & 63 & $\mathrm{R}$ & NS & $\mathrm{MuC}$ & $+/+$ & Asia, Japan & NS \\
\hline D. G. Ross ${ }^{11} 1986$ & $\mathrm{~F}$ & 59 & Horseshoe & 7 & MuC & NS / NS & N America, USA & NS \\
\hline Hasebe $^{9} 1960$ & NS & NS & NS & NS & $\mathrm{MCa}$ & NS/ NS & Asia, Japan & NS \\
\hline Nielsen ${ }^{4} 1957$ & NS & NS & NS & NS & $\mathrm{MuC}$ & $+/ N S$ & NS & NS \\
\hline Arcadi $^{7} 1956$ & NS & NS & NS & 30 & $\mathrm{MCa}$ & $+/ N S$ & N America, USA & NS \\
\hline Plaut $^{5} 1929$ & NS & NS & NS & NS & MuC & $+/ N S$ & NS & NS \\
\hline
\end{tabular}

CK: cytokeratin, EMA: epithelial membrane antigen, MCa: mucinous cystadenocarcinoma, MuC: mucinous cystadenoma, MUC: mucin, NS: not specified

metaplastic change, including (1) renal maldevelopment, (2) chronic inflammation (or irritation), and (3) celomic epithelium differentiation $[6,20]$.

Only three MCs and three MCCs were reported in association with maldevelopment $[6,8,18]$. Some authors suggested that such parenchymal tumors could originate from a sequestrated segment of the renal pelvic epithelium in renal parenchyma in the background of maldevelopment $[10,11,18]$. Most cases were associated with chronic irritation secondary to urolithiasis or pyelonephritis [3,13,18]. Renal calculi were reported among ten patients of MC's previous reports, six cases declared no calculi, and six studies did not mention the condition (Table 2). Four cases had pyelonephritis, and 
all of them were accompanying renal stones. Thus, pyelonephritis might be a result of the renal stone rather than a risk factor for MC. Three case reports declared no inflammatory state, such as renal stones or pyelonephritis [21]. Although we did not find a previous history of renal stone or infection, we detected histologic findings of chronic inflammation around the cyst. Finally, celomic epithelium differentiation and subsequent mucinous metaplasia are another possibility due to the high resemblance to ovarian mucinous neoplasms [22, 23].

In MC arising from the urinary collecting system, the cyst's inner surface is lined by mucin-producing columnar epithelium with the continuous transition to the urothelium $[15,18]$. In those arising from the renal parenchyma, including our case, the inner surface was covered only by columnar mucinous epithelium [3].

The noted information suggests that pelvic $\mathrm{MC}$ and parenchymal MC may have the same origin and evolve from a similar sequence of events: chronic irritation and epithelial invagination, then glandular metaplasia, and finally, neoplastic transformation [3].

\subsection{Diagnosis and differential diagnosis}

The diagnosis of MC was always made after nephrectomy (partial or total) in previous reports [6]. Differential diagnoses of muconephrosis are more frequent than MC. Solid renal cell carcinomas with necrotic or hemorrhagic components, metastatic mucinous cystadenocarcinoma of the appendix, renal papillary adenoma, villous adenoma (arising from urothelial metaplasia), and MCC are other possible diagnoses [6]. It is quite difficult to distinguish an MC from a simple cyst based on clinical history, physical, laboratory, and imaging findings. History of mucusuria should raise the suspicion of MC or MCC [24]. Other non-specific symptoms are flank pain and hematuria. Some cases had a palpable abdominal mass on physical examination. Overall, the presentation can vary from silent disease to pseudomyxoma peritonei [24]. Laboratory results are usually non-specific and inconclusive. Imaging studies may not differentiate benign $\mathrm{MC}$ of the kidney from malignant counterpart, thus complex renal cyst and renal cyst with mural nodule should be followed closely to detect malignancy in early stages $[20,21,25,26]$. Ultrasonographic features of a simple renal cyst include (1) ovoid or spherical shape, (2) distinct, sharp borders with a smooth margin, (3) no internal echogenicity, and (4) acoustic enhancement behind the cyst [10]. Akan et al. reported a case of MC that fulfilled all the above criteria [10]. It can somehow explain our patient's ultrasound findings of simple cyst one year before the presentation; the MC contains a thick fluid initially, which is hard to distinguish from a simple cyst; with time, the mucinous components form features of calcification secondary to mucin production [21].

CT scan also failed to distinguish MC from hydronephrosis and simple renal cyst because all these conditions pose -10 to $+20 \mathrm{HF}$ density $[18,27]$. We also found two case reports diagnosed with cystic adenocarcinoma with considerable similarities to our case, but no full texts available $[28,29]$.

Immunohistochemical studies: Such a profile can help to realize the lineage of the neoplasm. Chable et al. reported three MCs cases, which were diffusely positive for CDX2, MUC2, and CK20, which are sensitive intestinal tissue markers. Many studies showed cytokeratin-7 (CK 7), epithelial membrane antigen (EMA), and CEA positivity $[3,12,30,31]$. We did not perform IHC studies due to limited resources resulting from economic sanctions, like two other Iranian studies [32, 33]. The results of other studies are summarized in Table 2.

\subsection{Management}

In all previous reports, the exact diagnosis was made only after a total or partial nephrectomy. Regarding MCCs, because primary $\mathrm{MCC}$ is extremely rare, secondary involvement should be evaluated in organs with a higher prevalence of MCC (ovaries, pancreas, appendix). Two $\mathrm{MC}$ cases with carcinoid tumors were reported, and both had no carcinoid syndrome [34, 35].

\subsection{Prognosis}

The overall prognosis of RCCs with cystic characteristics is better than those with solid components [36]. However, the same pattern is not valid for MC and MCC because these cysts present themselves in different types of Bosniak classifications. Akan et al. presented a case of MC with radiologic features of a simple renal cyst [10]. Like the reported case of Mitome et al., our patient showed IIF Bosniak classification with MC's diagnosis [18]. Interestingly, Tepeler et al. and Tasmin et al. also presented cases with IIF Bosniak classification but MCC's diagnosis $[6,37]$. Other studies did not mention the Bosniak score.

\subsection{Follow-up}

We found no standardized follow-up schedule for MC of the kidney. It could be deduced that patients with MC may not require a hardline, strict follow-up, although it is necessary to evaluate patients regularly and cost-effectively. The rationale is that the criteria for determining the benign versus the malignant nature mostly derived from ovarian MCs, but the tumor's course is not thoroughly studied in the kidney.

In previous studies, there was no history of hypertension, hearing impairment, and anxiety. In this case, hypertension and anxiety might be due to the cyst's 
pressure effect on renal hilar vessels. Thus, surgical excision may lead to the return of blood pressure to a normal range. Hearing improvement may be due to antihypertensive medications' cessation; however, we have no explanation about anxiety and its amelioration after surgical excision. Another limitation of the present study is that we only searched the PubMed database for similar cases.

\section{Conclusion}

The primary MC of the kidney is extremely rare and quite difficult to distinguish from a simple cyst based on imaging studies. The histopathologic findings of previously reported cases, along with this case, suggest that the origin of pelvic MC and parenchymal MC may be the same. Finally, complex renal cyst and renal cysts with mural nodules should be followed closely to detect malignancy in earlier stages.

\section{Abbreviations}

MC: Mucinous cystadenoma; MCC: Mucinous cystadenocarcinoma; CK 7: Cytokeratin-7; EMA: Epithelial membrane antigen; CEA: Carcinoembryogenic antigen; IHC: Immunohistochemistry.

\section{Acknowledgements}

None

\section{Authors' contributions}

SS and BPR performed the nephrectomy. MK and SK made the pathological diagnosis, AA and MM wrote the manuscript and reviewed literature. All authors revised the final version. All authors have read and approved the manuscript.

\section{Funding}

Self-fund.

\section{Availability of data and materials}

All data regarding the present study is available by contacting the corresponding author.

\section{Declarations}

\section{Ethics and consent to participate}

Written and verbal consent were taken from the patient for participating in the study.

\section{Consent for publication}

Written and verbal consent was taken from the patient for publishing in the study results anonymously.

\section{Competing interests}

The authors declare that they have no competing interests.

\section{Author details}

${ }^{1}$ Department of Pathology, Faculty of Medicine, Mashhad University of Medical Sciences, Mashhad, Iran. ${ }^{2}$ Faculty of Medicine, Mashhad University of Medical Sciences, Mashhad, Iran. ${ }^{3}$ Kidney Transplantation Complications Research Center, Mashhad University of Medical Sciences, Mashhad, Iran. ${ }^{4}$ Nuclear Medicine Research Center, Mashhad University of Medical Sciences, Mashhad, Iran. ${ }^{5}$ Kidney Transplantation Complications Research Center, Mashhad University of Medical Sciences, Mashhad, Iran.
Received: 24 October 2020 Accepted: 11 July 2021

Published online: 23 July 2021

\section{References}

1. Han DS, Yuk SM, Youn CS, Park G, Sul HJ, Jang H (2015) Primary mucinous cystadenocarcinoma of the renal pelvis misdiagnosed as ureteropelvic junction stenosis with renal pelvis stone: a case report and literature review. World J Surg Oncol 13(1):1-5

2. Patel RD, Vanikar AV, Modi PR (2014) Transplantation. Mucinous cystadenocarcinoma of renal pelvis presenting as pyonephrosis. Saudi J Kidney Dis Transp 25(3):647

3. Chablé-Montero F, Mendoza-Ramírez S, Lavenant-Borja MI, GonzálezRomo MA, Soto-Abraham V, Henson DE et al (2013) Mucinous cystadenoma of the pyelocaliceal system: a report of 3 examples and an analysis of 17 previously published cases. Ann Diagn Pathol 17(3):239-244

4. JB N (1957) Sjelden nyrebaekken-tumor. Nord Med, 58: 1774-1775

5. Plaut A (1929) Diffuses dickdarmahnliches Adenom des Nierenbeckens mit geschwulstartiger Wucherung von Gefassmuskulatur. Ztschr f urol Chirt 26:562-578

6. Tamsin A, Schillebeeckx C, Van Langenhove C, Vander Eeckt K, Ost D, Wetzels K (2019) Mucinous cystadenocarcinoma in the renal pelvis: primary or secondary? Case report and literature review. Acta Chirurgica Belgica.1-8

7. Arcadi JA (1956) Mucus-producing cystadenocarcinoma of the renal pelvis and ureter; fourth reported case. AMA Arch Pathol 61(3):264

8. Muraoka K, Osada Y (1997) Cystadenocarcinoma of renal pelvic origin in a supernumerary kidney. Ryoikibetsu shokogun shirizu (16 Pt 1): 453

9. Hasebe M, Serizawa S, Chino S (1960) On a case of papillary cystadenocarcinoma following malignant degeneration of a papillary adenoma in the kidney pelvis. Yokohama Med Bull 11:491

10. Akan H, Dalva I, YILDIZ Ö, Kutluay L, GÜNDOĞDU S, GÜNGEN Y (2005) Mucinous cystadenoma mimicking simple renal parenchymal cyst in a horseshoe kidney. Int J Urol 12(5):493-496

11. Ross D, D'Amato NA (1985) Papillary mucinous cystadenoma of probable renal pelvic origin in a horseshoe kidney. Arch Pathol Labor Med 109(10):954-955

12. Charfi S, Ayadi L, Khabir A, Gouiaa N, Fakhfakh I, Bahri I et al (2008) Le cystadénome mucineux du rein. Prog Urol 18(9):613-616

13. Kumar B, Agarwal RK, Upadhyay P (2009) Mucinous cystadenoma of the kidney. Ind J Pathol Microbiol 52(2):274

14. Arakawa M, Jimi A, Ootomi M, Ooyabu Y, Samejima H (1989) A mucinproducing cystadenoma, borderline malignancy, of the renal pelvis and ureter: a case report. Gan no rinsho Japan J Cancer Clin. 35(4):499-504

15. Gangane N, Anshu A, Shende N, Sharma SM (2008) Mucinous cystadenoma arising from renal pelvis: a report of 2 cases. Urol Journalo. 5(3):197-199

16. Ohyabu Y, Sameshima H, Eto K (1990) Mucin-producing cystadenoma (borderline malignancy) of the renal pelvis and ureter. A case report. Nihon Hinyokika Gakkai zasshi Jpn J Urol 81(6):913

17. Park S, Meng MV, Greenberg MS, Deng DY, Stoller MLU (2002) Muconephrosis. Urology 60(2):344

18. Mitome T, Yao M, Udaka N, Fusayasu S, Izumi K, Osaka K, et al. (2015) Mucinous cystadenoma of a horseshoe kidney: a case report and literature review. 9(1-2): E30

19. Mardi K, Sharma J, Mahajan P (2006) Mucinous cystadenoma of the renal pelvis with malignant transformation: a case report. Ind J Pathol Microbiol 49(4):595

20. Kim SH, Yuk HD, Park WS, Kim SH, Joung JY, Seo HK et al (2016) A case report of partial nephrectomy of mucinous cystadenocarcinoma in kidney and its literature review. Cancer Res Treat Offic J Korean Cancer Assoc 48(2):838

21. Xiang H, Zhang X, Ba X, Wu W (2017) E. Mucinous cystadenoma with calcification arising from renal pelvis radiologically resembled renal calculus with hydronephrosis: report of a rare case and review of the literature. Int J Clin Exp Pathol 10(8):8756

22. Rao P, Pinheiro N Jr, Franco M, Ra S, Costa H, Manzano J et al (2009) Pseudomyxoma peritonei associated with primary mucinous borderline tumor of the renal pelvicalyceal system. Arch Pathol Labor Med 133(9):1472-1476 
23. Raphael V, Sailo S, Bhuyan A, Phukan M (2011) Mucinous adenocarcinoma of the renal pelvis with adenocarcinoma in situ of the ureter. Urol Ann 3(3):164

24. Yadav R, Kataria K, Balasundaram P, Karak MD AK (2013) Mucinous cystadenocarcinoma arising in an ectopic kidney simulating a retroperitoneal dermoid cyst: a rare tumour presenting as a diagnostic dilemma. Malaysian J Pathol, 35(1)

25. Kaur G, Naik V, Rahman M (2004) Mucinous adenocarcinoma of the renal pelvis associated with lithiasis and chronic gout. Singapore Med J 45(3):125-126

26. Mikami M, Tei C, Takehara K, Komiyama S, Suzuki A, Hirose T (2003) Retroperitoneal primary mucinous adenocarcinoma with a mural nodule of anaplastic tumor: a case report and literature review. Int J Gynecol Pathol 22(2):205-208

27. Leena SK, Rajendiran S, Kripesh G, Sekar H (2016) Mucinous cystadenocarcinoma in a horse shoe kidney masquerading as giant hydronephrosis - a case report: diagnostic challenges, lessons learnt and review of literature. J Clin Diagn Res 10(11):12-14

28. Garrido RC, Sanromá OI, Garmendia LJ, Ruiz DI, López GJ, Arocena LF (1990) Cystic renal adenocarcinoma. Arch Esp Urol 43(9):1015

29. Yamamoto N, Maeda S, Takeuchi T, Kuriyama M, Mizoguchi Y, Kasahara M et al (1992) Cancer of the kidney mimicking renal multilocular cyst. Progres en urologie: journal de l'Association francaise d'urologie et de la Societe francaise d'urologie 2(2):258-262

30. Sonmez FC, Esen HH, Tavlı L, Kılınç M (2014) Well-Differentiated Mucinous cystadenocarcinoma of the renal pelvis. Eur J Gen Med 1:63-65
31. Toyoda H, Mabuchi T, Fukuda K (1997) Mucinous cystadenoma with malignant transformation arising in the renal pelvis. Pathol Int 47(2-3):174-178

32. Geramizadeh B, Khezri A, Giti RJ (2017) Incidental mucinous adenocarcinoma in situ of renal pelvis presenting as severe hydronephrosis. J Nephropathol, 6(4)

33. Fareghi M, Mohammadi A (2009) Madaen K (2009) Primary mucinous cystadenocarcinoma of renal pelvis: a case report. Cases J 2(1):9395

34. Kawahara T, Nagashima Y, Misaki H (2009) Primary renal carcinoid tumor with a mucinous cystadenoma element. Int J Urol 16(11):920-921

35. Takashi M, Matsuyama M, Furuhashi K, Kodama Y, Shinzato M, Shamoto M et al (2003) Composite tumor of mucinous cystadenoma and somatostatinoma of the kidney. Int J Urol 10(11):603-606

36. Silverman SG, Pedrosa I, Ellis JH, Hindman NM, Schieda N, Smith AD et al (2019) Bosniak classification of cystic renal masses, version 2019: an update proposal and needs assessment. Radiology 292(2):475-488

37. Tepeler A, Erdem MR, Kurt O, Topaktas R, Kilicaslan I, Armağan A, et al. (2011) A rare renal epithelial tumor: mucinous cystadenocarcinoma case report and review of the literature. Case Rep Med, 2011.

\section{Publisher's Note}

Springer Nature remains neutral with regard to jurisdictional claims in published maps and institutional affiliations.

\section{Submit your manuscript to a SpringerOpen ${ }^{\circ}$ journal and benefit from:}

- Convenient online submission

- Rigorous peer review

- Open access: articles freely available online

- High visibility within the field

- Retaining the copyright to your article

Submit your next manuscript at $\boldsymbol{\nabla}$ springeropen.com 